\title{
CONSIDERING COMPLEXITY: TOWARD A STRATEGY FOR NON-LINEAR ANALYSIS
}

\author{
Ken HATT ${ }^{1}$
}

\begin{abstract}
This paper explores complexity and a strategy for non-linear analysis with a consistent ontological, epistemological and methodological orientation. Complexity is defined and approaches in the natural sciences, ecosystems research, discursive studies and the social sciences are reviewed. In social science, theoretical efforts associated with problems of social order (Luhmann), critical sociology (Byrne) and post-structuralism (Cilliers) as well as representative studies are examined. The review concludes that there is need for an approach that will address morphogenesis and facilitate analysis of multilateral mutual causal relations. The remainder of the paper approaches these matters by outlining Archer's approach to morphogenesis, Maruyama's morphogenetic casual-loop model of epistemology and illustrating Maruyama's method for analysis which employs both positive and negative feedback loops. The result is a strategy based on morphogenetic causal loop models that can be used to analyze structuring and the connections through which structures may be reproduced or transformed.
\end{abstract}

Keywords: complexity, nonlinearity, critical realism, morphogenesis, epistemology, methodology

Résumé. Cet article porte sur la complexité et la stratégie d'analyse non linéaire d'un point de vue ontologique, épistémologique et méthodologique constant. La complexité y est définie, et les approches en termes de sciences naturelles, de recherche en écosystèmes, en études discursives et en sciences sociales y sont examinées. En termes de sciences sociales, l'effort théorique associé aux problèmes d'ordre social (Luhmann), de sociologie critique (Byrne) et de poststructuralisme (Cilliers) ainsi que des études représentatives y sont examinées. En conclusion, il existe un besoin pour une approche abordant la morphogénèse et facilitant l'analyse de relations causales multilatérales. Le reste de l'article aborde ces questions en énonçant l'approche d'Archer à la morphogénèse, le modèle d'épistémolo-

1. I would like to thank Kierstin Hatt for her insights into complexity, sociology and her support, my colleagues Bill Carroll and Martha McMahon for discussion and encouragement, and Jim Hills, Ted Menmuir, and David Yetman for their discussions on this matter. Finally, I also thank the editor and the four reviewers who made challenging and critical comments that, hopefully, made this a better paper. 
gie de boucle causale de Maruyama et l'illustration de la méthode d'analyse de Maruyama qui a recours à la fois aux boucles de rétroaction positive et négative. Le résultat sert à une analyse de la structure et aux connexions à travers lesquelles les structures peuvent être reproduites ou transformées.

Mots clés : complexité, non-lineaire, réalisme critique, morphogénèse, épistémologie, méthodologie

\section{INTRODUCTION}

$\int$ his paper explores complexity and a strategy for analyzing complex social phenomena. Matters such as SARS, BSE, and global warming call for moving beyond conventional linear approaches and the changing nature of science justifies an enhanced role for sociology, perhaps greater than ever before. It should be no surprise that complexity has been central in efforts to revitalize three major domains of sociology: social order (Luhmann 1995), critical sociology (Byrne 1998) and poststructuralism (Cilliers 1998). Matters like these exacerbate concerns about philosophical questions regarding knowledge, science, and epistemology that have been especially contentious in recent years. I approach them viewing knowledge, not as just produced by autonomous individuals, but as contingent upon and regenerative of linguistic communities. It is seen not as a categorical matter residing solely in the domain of philosophical analysis, but as a sphere of cognitive, social, and cultural activity in a continuum between the embodied organization of experience and ideological production. Nor is knowledge seen as a monopoly of science, victim of radical uncertainty, or projection of language games. The urge to reduce epistemology to language games is resisted, as is expanding it to exclude considerations of ontology. The absence of a universal answer to the question of how we know does not mean that there are no answers or that there is no use in discerning among alternatives. These difficulties have been addressed in a variety of ways ranging from the normal science canon and its revival around "methodological fundamentalism" (Lincoln and Cannella 2004) to realist stances and antifoundational views often associated with poststructuralism. The position taken here is closest to critical realism despite reservations about promises of its emancipatory potential. Instead, contributing to critical social science through a model for exploring complexity based on the insights of the ecosystems researchers and the techniques of Maruyama is envisioned here $(1960 ; 1962 ; 1978){ }^{2}$

2. This paper is part of a project in "postnormal" sociology. Although irritating, the term is chosen as an attractor for an alternative within sociology to "normal" (i.e., Newtonian, linear-based) sociology. Two major disruptors of "normal" sociology are complexity and paradoxicality - the former is explored here. The project also explores be- 
An episode of "mad cow" disease in England (Funtowicz 1998) illustrates the tenor of matters being explored in this paper. Funtowicz recalls that scientific experts had assured the British government for years that the risk of humans being infected was not significant. When it did occur, however, public alarm and the costs to the government were significant. The initial response was acknowledgement, followed by stonewalling that led to a moral panic which threatened the British and European meat industries. The result was a situation in which a hard decision about destroying cattle had to be based on soft estimates of how extensive the impact would be and what was needed to reverse the situation. It was a problem that adding more data or computer power would not solve. The situation institutionalized around politicization that became part of the complexity. Diversity of perspectives and competing academic models exacerbated the problem. In addition, social and political advocates not formerly acknowledged became part of a new network as decision making was extended in order to absorb the critique. This example illustrates how complex systems that are inherently uncertain in many respects can be further complicated by existing social, political, and economic systems that are composed of many stakeholders with competing values. It also suggests the value of integrating complexity and strategies for dealing with it into our conventional analytical systems.

\section{Defining Complexity}

In this paper, complexity is defined as a type of intricate relationality constituted in and around structures that are self-organizing, dissipative, dynamic, nonlinear, and indeterminate. Pribram (1996:41) points out a paradoxical feature of complexity from its etymological derivation as an assemblage of interconnected parts with an intricate internal structure.

Complexity is thus shown to encompass two levels of scales - a multiform interior or micro-level and a macro-level whole ... [it is] an intricate diverse micro-level embraced within a simpler macro-level entity - unity in diversity.

Complexity also applies to the research process, making the conventional normal science procedure of fitting the model to the problem itself problematic. For example, Kay and Schneider (1994:35) note there is an observer-dependent characteristic when studying self-organizing systems that makes linear analysis dysfunctional.

ing "postnormal" and doing "postnormal" sociology, which revolves around embodied, nonlinear strategies for defending against and resisting the system-world. 
Discussions of complexity generally focus on complex systems. The notion of a system is, of course, a social construction referring to a set of elements contained within a boundary that distinguishes them from those that are outside, in its environment. Funtowicz (1998) distinguishes between simple, complicated, and complex systems, suggesting that two key features of complex systems are significant and irreducible uncertainties and a multiplicity of legitimate perspectives on any problem. Although numerous examples could be given, Ellis (2004) provides a specific list: "molecular biology, animal and human brains, language and symbolic systems, individual human behavior, social and economic systems, digital computer systems and the biosphere." There is an emerging consensus among those addressing complexity, whether in discursive, social scientific, or natural science studies, that there are serious limitations in using linear strategies or singular disciplinary perspectives when dealing with complex systems (Harvey and Reed 1996; Holling 1994; Kauffman 1993; Ragin 2006; Reed and Harvey 1992; Schneider and Kay 1994; Urry 2003).

Complexity can be further clarified by distinguishing it from chaos, which has an affinity but is distinct (Bak and Chen 1991; Elliott and Kiel 1997; Eve et al. 1997; Hayles 1991b). Chaos surfaced in the 1970s as a result of a discovery by Lorenz that feedback operates unpredictably in iterations of sequences of some sets of simultaneous equations (Eve 1997:270). There was a sensitivity to initial conditions that made longterm prediction impossible (Elliott and Kiel 1997:67). The unpredictability was not totally random as has been suggested in some accounts of chaos. That is, sequences in various iterations would move around unpredictably, with a tendency to stabilize around points that came to be known as attractors (Cilliers 1998; Mackenzie 2005; Urry 2005). Lorenz noted that these chaotic regions revolved around two attractors in a manner that looked like the wings of a butterfly, hence the designation "butterfly effect" (Casti 1994). Other attractors, with more disparate patterns were referred to as "strange attractors" (Eve et al. 1997). The examination of these fluctuations revolved around concepts such irreversibility, dissipation, and bifurcation. In the first, an initial system is changed irreversibly to another product, such as in scrambled eggs or mayonnaise. Whether or not external elements have been involved, the original product and its elements cannot be returned to their original state. This may involve a process of self-organization. Dissipation refers to the way in which energy is expended or scattered within a system and is associated with the instabilities that may be chaotic. In this process a system goes through a series of fluctuations associated with increasing tension or instability and, at a bifurcation point, splits away from its ori- 
ginal state. It was Prigogine and colleagues $(1980 ; 1984)$ who showed that these spontaneous fluctuations, previously characterized as average tendencies, were crucial in accounting for the emergence of new forms of organization. It is now clear that the expansive claims about chaos were overstated, but two important features still seem correct: 1) chaos occurs within certain parameters, contradicting claims about its total indeterminacy, and 2) uncertainty is inevitable for many phenomena, undermining confidence in mathematical precision to provide longrange prediction (Eve 1997:xxix). Elliott and Kiel (1997:66) say chaos is a manifestation of nonlinearity found in complex systems which are more complex and unpredictable than chaos. Two specific differences between chaos and complexity are that first, chaotic behaviour usually results from the nonlinear interaction of a few equations while in complex systems many components are interacting (Cilliers 1998:ix). Second, chaotic behaviour exhibits a sensitivity to initial conditions, which is not the case for complex systems that are, in some cases, quite robust and capable of persisting in response to a variety of conditions (Cilliers 1998; Hayles 1991a). Chaos can be seen, then, as a possible precursor or manifestation of complexity.

\section{Four Key ORIENTATIONS TO COMPLEXITY}

The literature on complexity can be examined through four domains of inquiry: 1) the natural scientific approach which takes mathematics as the ideal language of science; 2) an ecosystems approach that stresses self-organization, unpredictability, and ecosystem intersection with social systems; 3 ) poststructuralist views of complexity and science as part of a larger sociocultural project; and 4) social scientific efforts to reform conventional linear-based practices.

\section{A. Complexity as Indeterminate}

The notion of complexity is most commonly associated with work in mathematics, physics and biology on chaos. For example, Back (1997) approaches complexity using mathematics not only as the central technique of representation but as a source of authority, as seen in the randomness associated with mathematical equations that developed chaos theory. Saperstein (1997:121) uses complexity theory as a paradigm for deterministic iterations in small random disturbances that arise outside a model. Hübler (2007) refers to these approaches as "computational complexity theory" revolving around the running and memory time involved in computing algorithm change in equations. In biology, Kauff- 
man (1993:175) proposes a "mathematical theory of dynamical systems" as a "natural language" for dealing with some complex systems. Perhaps the most well-known approach is that of Shannon (Shannon and Weaver 1963), who treated communication as a digital and stochastic process, devoid of content, and measurable in terms of the information carried by a system. He proposed using the way in which information is processed or exchanged in a system as a measure of complexity (Lloyd 1990). The more orderly a system is, the more redundancy it carries and so less information is needed to describe it. Since most information is required in messages whose content is completely random, according to this criteria, they would be the most complex (Cilliers 1998:8). The mathematicalbased approach from which chaos developed has been predominant, but Goertzel (1997), for example, in combining algorithmic patterns of systems dynamics with autopoiesis, illustrates how it has sometimes incorporated developments from other domains as well.

\section{B. Ecosystem Complexity}

In recent years ecosystems researchers have emphasized the importance of paying close attention to the complex features and dynamics of ecosystems and their interconnectedness with social systems. Much of the work can be traced to Ilya Prigogine and colleagues $(1980 ; 1984)$, whose research revolved around dissipative structures and hierarchy in ecosystems (Allen and Starr 1982). From it C.S. Holling (1986; 1994) constructed a paradigm of complexity in ecological systems based on a diversity that is nonlinear, indeterminate, open, and consistently generating surprise. Holling rejected equilibrium-centred notions of ecosystems and the assumption of constancy in favour of dynamic processes in ecosystems involving mobilization, conservation, exploitation, and creative destruction often culminating in abrupt change (1994:607-608). He asserted that ecological complexity is relative to a frame of reference where there is a continuing sense of paradox between the frame and perceived reality. This is due to a bewildering diversity of thousands of organisms (including humans). This emphasis was extended by another group of ecologists who characterize complex systems as Self-Organizing, Holarchic, Open (SOHO) systems that are indeterminate and inherently involve humans (Kay and Regier 2000; Kay and Schneider 1994). They argue that the traditional role of the scientist as a problem-solver requires supplementation with an alternative approach capable of dealing with complex systems. They also stress the urgency of developing an adaptive approach since ultimately, "human systems are utterly dependent on natural systems for their context" (Kay and Regier 2000:152). 


\section{Complexity as Discursive Project}

Hayles (1991) and Mackenzie (2005) trace the cross-fertilization of chaos and complexity in the natural sciences and the humanities, seeing their potential for liberating literature, philosophy, and drama from a dualistic epistemological orientation. Complexity is seen as a metaphorical configuration constituted within a sociocultural context involving a relation between writer, reader, text, and culture. Examples are found in the work of Porush (1991), who sees scientific and fictive discourse as complementary with dissipative structures; Thrift (1999), who traces the career of complexity as a commodity in corporate development; and Bainbridge (1997), who associates the rise of complexity with the "omicron point" - being discovered when humanity is ready for it. Stewart (2001) approaches complexity as a metatheory that is derived from "theories of nonlinearity." Ironically, though his view of complexity is strikingly intricate, he rejects its analytical usefulness. This is because he sees complexity as based both on mathematical standards of Newtonian science and social processes that are embedded in language. As a result, he concludes that rigorous analysis of complex phenomena is not feasible. Brian Wynne (2005) traces the way complexity has been domesticated in his examination of postgenomic science. He shows how a reductionist strategy emerged in science, foreshadowing the colonization of public awareness regarding science. This is seen in simplistic conceptualizations such as: one gene $\rightarrow$ one protein $\rightarrow$ one behavioural trait. This view emerged shortly after Watson and Crick's publication on the double helix structure of DNA (Watson 1968). Wynne documents how, despite continued critique even from within the discipline, this view has expanded. It grew in the late 1980s, around laboratory research and predictive modeling found in big pharmaceutical and GM science. As a result, complexity and its reductionist clone are intertwined as objects of attention that are projected onto society, that is, performed. Performances have their roots in the traditional vision of science and public mistrust of science that serve to "frame" scientific legitimacy. Reductionist science is enhanced by the notion of the "public deficit," a myth promulgated by institutional science that because publics mistakenly expect certainty, any admission of failure would threaten the legitimation of science (2005:78-88). Wynne argues that complexity has been redefined as what is predictable and controllable, especially through notions such as risk assessment. As a result, uncertainty has replaced ignorance, which is no longer acknowledged. This view has been projected upon the scientific imaginary so that the scientific management of public conceptions has "become integral to scientific knowledge-generation" (2005:68). As 
can be seen from these accounts, the discursive approach informs our sensibility of complexity by articulating its symbolic, existential, and ontological qualities.

\section{Complexity as Social Reality}

Social scientists vary in their approaches to complexity, but most activity seems to revolve around either integrating it into comprehensive theoretical projects (Luhmann 1989; 1995; Cilliers 1998; 2005; Byrne 1998; 2005) or understanding specific topics (Artigiani 1987; Garcia 2000; Knapp 1999; Summers-Effler 2007; Urry 2003; 2005; Walby 2007). Turning to the former, one finds theoretical efforts associated respectively with problems of social order, poststructuralism, and critical sociology. The first of these is the quest by Niklas Luhmann for a universal theory of society based on systems theory and its two major concepts: system and environment. System and environment become operational due to a process of differentiation, which occurs not in consciousness but in the world of experience, through communication. Through successive repetition a system achieves autopoiesis, a process that transforms itself into itself through recursive closure that is regulated by communication. Social systems are comprised of communication, not persons or actions, and the concept "society' is reserved for the all-encompassing social system of mutually referring communications" (Luhmann 1989:7). Functional differentiation leads to key social systems such as economy, law, science, politics, religion, and education which are constituted as autopoietic communications networks revolving around binary codes such as: possession of money and nonpossession, legal and illegal, true and false, conservative and progressive, immanence and transcendence, and pass and fail (Bjerg 2006). Reproduction of a system depends on its ability to reduce the complexity of the environment through processes of selection and actualization of potential observations that, in turn, lead to an increase in complexity within the social system.

Complexity, in the first instance, is "the impossibility of connecting all elements together, the impossibility of complete observation and representation of phenomena that would require connecting each element with every other element" (Luhmann 1995:55). Secondarily, as the complexity of the environment is reduced through selective responses by systems, it increases within social systems. Complexity is seen, then, as an otherness against which systems counterdependently distinguish themselves, which is then incorporated through successive recursion. Luhmann describes complexity as a special horizon of system operations in the interpenetration of systems (1995:231). 
The result is that complexity is translated into a limit against which autopoietic and self-referential processes operate. The environment "is only a negative correlate of the system. The environment is simply "everything else"" (1995:181). Likewise, "[e]cology has to do with a complexity that is not a system because it is not regulated by a system/environment difference of its own ... (ecosystem should be eco-complex)" (1995:31).

Luhmann has been criticized for a preoccupation with systemicity and an abstract view of the social world that conceals complexity, obscures external considerations, and misapprehends obvious empirical realities (Mingers 2002; Østerberg 2000; Smith and Jenks 2005; Stewart 2001; Viskovatoff 1997). Baumgartner (1986) says sociocybernetics should not be thought of as the application of cybernetics to social systems, but rather as the cybernetics of social systems. Yet Luhmann's work appears to violate that maxim in his fundamental statement: "The following considerations assume that there are systems ... the concept of system refers to something that is in reality a system and thereby incurs the responsibility of testing its statements against reality" (1995:12). In addition, Luhmann's model of autopoiesis was taken from the work of biologists Maturana and Varela (1980). Their work was not intended to provide an explanation, but a derivation of the phenomenology of the cell from the phenomenology of autopoiesis. The result is an autopoietic theory that is not explanatory, but a description of certain kinds of systems (Viskovatoff 1997:489-490). As a result, epistemology is reduced to questions of self-reference, a strategy that Luhmann apparently applauded (Baecker 2001; Luhmann 1995). According to this view, questions of final justification can only be answered within self-referential theories of self-referential systems - that is, "within the logic of universalistic theories that forces them to test on themselves everything they determine about their object" (Luhmann 1995:485). In justification for his position Luhmann (1995:446) stated:

Communication is the social system's only guarantee of reality - not because it reflects the world as it really is or describes it correctly ... but because it can be conditioned by the form of its closure and thereby subject itself to the test of proving its success.

In assuring his readers that dialogue created around self-referentiality is justified, Luhmann resorts to "an old, insightful rule, truths emerge conjointly, but error in isolation" (Luhmann 1995:58). After nearly five hundred pages of dancing with paradox, the reader is left with little more than Karl Mannheim's version of relationism (Lee 2000; Luhmann 1995; Mannheim 1961). 
Luhmann did, however, did set out an alternative perspective to the view of society as an agent-based, homeostatic, closed system. Reading his Social Systems is a continuous exercise in open-system thinking. He was uninterested in accounting for the dynamic by which structure is related to agency - associated with action theory - which he rejected. Even this position is not without criticism. Viskovatoff (1977:282) shows that because Luhmann refused to address the relation between structure and individual behaviour, he was unable to take into account the distinction between syntax and semantic, a central distinction in semiotics. In addition, in rejecting action theory, Luhmann embraced the principle of "order from noise" i.e., that consensus is invented rather than being preordained in a normative structure (Luhmann 1995:105). Smith and Jenks (2005:160) point out that as a result, his description lacks complexity since, for example, "terrestrial ecology is not order from noise but order from order and noise." Finally, Medd (2001) states that Luhmann's top down approach, emphasizing differentiation, ignored key factors in structure that require a bottom up emergence approach. Luhmann barely acknowledged contemporaneous developments in morphogenesis - an alternative that was probably not entirely consonant with his central notions of self-reference and autopoiesis. ${ }^{3}$ In sum, as a guide for exploring complexity, this formulation is bare, inviting preoccupation with permutations of social complexity through processes of differentiation and autopoiesis.

Paul Cilliers $(1998 ; 2005)$ explores an analogical relationship between a connectionist model of the brain and a poststructuralist approach to language as the basis for framing a theory of complex systems. Recent developments in science and philosophy lead him to conclude that complete knowledge of complex systems cannot be achieved and there is no secure foundationalist position from which to work. As a result, he brings together deconstructionist features of poststructuralism and cognitive science to produce an interpretive and exploratory understanding of complexity aimed at recognizing the limits of scientific knowledge and its practice (1998:129). Cilliers' connectionist model derives from work in cognitive sciences on neural networks (1998:25) and revolves around the concept of distributed representation, where meaning is conferred through relationships between structural components within a complex system rather than by a set of rules that may be described according to

3. It is somewhat surprising, since Luhmann was encyclopaedic in his coverage of relevant material. He cites Prigogine and Maruyama, but crucial features of morphogenesis, such as the irreversibility or the interaction of positive and negative feedback loops is not integrated into his work. He does refer to morphogenesis, approaching it as an option worth exploring (Luhmann 1995:351-356). 
the idea of correspondence (1998:11). Structure emerges as local units compete and cooperate for resources in nonlinear relations that are distributed, weighted, and stored as traces of memory (1998:94-95). Neural networks are robust: they implicitly deal with complexity rather than requiring an algorithm, and they can generalize solutions (1998:69-71). The relational features of cognition and the capacity for self-organization lead to complex structures that are able to conserve complexity. Hence, the process of self-organization creates an internal structure in connectionist networks that does not require a notion of central control. Meaning, then, is structured, and involves a historical and dialectical process that is affected, but not determined, by external processes. Distributed representation is seen as analogous to the poststructuralist conception of language (1998:141). Cilliers adopts Derrida's modifications of Saussure whereby language is approached as an open system that precedes meaning (1998:42-45). Meaning is constituted in a play of signifiers, signs that are "unanchored," but constituted as a collection of interactive cognitive associations through which they obtain their significance. Meaning is never given, but only temporarily consolidated around "pockets of stability" (Stofberg 1988). It revolves around processes of interpretation in which signs are not only produced by systems, but are also involved in the production of a system. As a result, meaning is never simply present and we cannot escape the process of interpretation.

Abstracting from the equivalence between the model of neural networks and the poststructuralist approach to language, Cilliers develops a description for a framework to theorize complexity. Complex systems are characterized by large numbers of elements that interact at fairly short range in a rich, nonlinear, and dynamic way. As open systems, they operate under conditions that are far from equilibrium and have histories with loops in their interconnections. In general, complex systems have two key capabilities: 1) an ability to store information concerning the environment for future use (through distributed representation); and 2) the ability to change and develop internal structure without $a$ priori necessity of an external designer (self-organization) (1998:10). Cilliers differentiates his work on complexity from the classical research on chaos by tracing the way sand dunes can be seen as complex systems whose trajectories reflect self-organized criticality (Bak and Chen 1991). That is, the dynamics of a complex system can revolve either around stabilized relations with attractors, unstable relations associated with repellors, or some combination of the two (1998:97). Cilliers argues that a self-organizing system will try to balance itself at a critical point between rigid order and chaos. This is due, he argues, to a "natural" drive to optimize its organization towards a more complex 
structure that is associated with an "economic" goal of maximizing use of resources (1998:97).

In line with his open systems approach, Cilliers explores problematic areas in his own work, two of which will be described here. The first refers to differences between his connectionist model and the conventional model of representation that is based on rule-based analytical models. Rule-based systems are used to create a model of how a system is governed by establishing rules that reflect the logical relationships between symbols defined to directly reflect concepts. Cilliers argues that such an approach is faulty because, drawing on the work of Putnam (1981), meaning is holistic; in part, a normative notion; it depends on the environment and is a historical concept (the states of a complex system are in part derived from the history of the system). Cilliers proposes an alternative approach, based on Baudrillard (1988) which uses "simulation," and computer technology. Through it, he argues it is possible avoid the metaphysical problems of "representation" that arise from designing models which use organizational logic and relations between symbols and concepts (Cilliers 1998:86).

A second problematic area follows from his rejection of foundationalism, thus, inviting a charge of relativism. Cilliers argues that when someone claims anyone failing to subscribe to foundationalism is a relativist, they are approaching the problem in a simplistic manner. $\mathrm{He}$ argues that affirming the complexity of things and the limitations in our knowledge is simply acknowledging the present situation (2005:260). Since there is no secure foundationalist position from which to work, he sees establishing a more equitable relation between philosophy, the creative arts, and science as a way to avoid a potential "well-managed dystopia of a brave new world" (2005:265). He stresses the importance of taking responsibility, proposed by Cornell (1992) as an antidote to relativism: "We therefore do follow principles as if they were universal rules, but we have to remotivate the legitimacy of the rule each time we use it" (1998:139). Despite his tentative ontological and epistemological position, Cilliers' work is congenial to an emerging vocabulary of complexity and offers promising analogical relations between fundamental areas in social science: the brain and language.

A third effort in developing complexity comes from the work of David Byrne (1998; 2005). Byrne calls for a complexity science that grounds social science in both an ontological recognition of the contingency of reality and the possibility of engagement through knowledgebased, democratic politics. Byrne tries to correct limitations in Newtonian science by developing ways to undertake research appropriate for nonlinear, dissipative phenomena. Complexity theory is defined as: "the 
interdisciplinary understanding of reality as composed of complex open systems with emergent properties and transformational potential" (Byrne 2005:97). Byrne seeks to develop a "conceptual framework founded on the centrality of the forms and processes of deterministic chaos ... [in which] all systems are analogically dissipative" (1998:47). This carries with it key corollaries that knowledge is dynamic, inherently local rather that universal, and foundationalist, without being reductionist or positivist. Drawing on the work of Reed and Harvey (1992), his intent is to discover complexity, not in general laws, but through identification of the causal components, which explain how systems produce phenomena (2005:101). Complex systems are dynamic and open, yet nested, with emergent properties that lead to qualitative transformation. They are also dissipative i.e., subject to both internal and external sources of change; and have capacities for increasing internal structuration by importation of energy and exportation of disorganization to the immediate environment (Byrne 1998:30, citing Reed and Harvey 1992:377-378). Causation is understood to be both conjunctural and multiple, combining "in different and sometimes contradictory ways to produce the same outcome, revealing different paths" (2005:106, citing Ragin 2006:15). Likewise, different causal combinations could produce the same outcome. While hierarchy is present, it is not determinative since impact can move in both directions. Byrne says it is essential to examine the history of system trajectories in order to understand the way in which phase changes and transformations occur. Points of bifurcation around which oscillations and contingency occur are critical features in this dynamic, possibly leading to alternative structures around attractors. As he puts it "[s]mall changes make for big differences and lots of things are out to play, together" (1998:18). Along with Reed and Harvey, Byrne (1998:31) is more interested in the question "How do mechanisms producing social order periodically produce chaos and pave the way for radical social transformations?" rather than the conventional question, "How is order possible?"

Byrne holds that a shift to complexity makes it possible for social science to move toward policy formulation and practices based on more comprehensive understanding and public dialogue (2005:100). He argues that it is necessary to avoid the three paths of simple science, simple complexity, and poststructuralism. Simple science is the classical view of social science calling for the establishment of universal laws based on causation as a contest between variables in which each causal condition has an independent impact on outcomes and knowledge of laws enables prediction of future states of a system (citing Ragin 2006:97-106). The problem is that it does not provide a means for nonlinear analysis. 
A second path Byrne wishes to avoid is that of simple complexity (like Wynne, above) which substitutes the development of simple rules for scientific laws in accounting for emergent complexity. If the simple science proceeds through techniques such as simultaneous equations, simple complexity relies on simulation modeling. He argues that in a simulation the rules define the range of action of components of a system and simply describe how things get done. He adds, "knowledge of the rules does not, in principle, allow us to predict in this way. Rules are not laws. Laws describe the behavior of the system as a whole" (2005:102). $\mathrm{He}$ argues further that only the simplest mathematical models can be validated and that the equation set describes a mathematical model. This approach appears attractive "because ... it can establish rules which seem to describe lots of systems and the establishment of rules has the same general character as the establishment of laws" (2005:103). Despite this critique, he does not dismiss the techniques, for he sees that they may have value when applied to some problems. He is concerned, instead, about the reductionism they encourage and the potential for social engineering involved in technocratic elitism and market-oriented research such as the "crude positivism in which the randomized controlled trial is hailed as the 'gold standard of evaluation"” (2005:100).

A third path Byrne wishes to avoid is that of poststructuralism. Without denying that science has a social nature, he is opposed to social construction being elevated to a unilateral position by poststructuralism. He opposes the relativism that arises from such a position, in part, because he believes it is based on a false dichotomy between the domination of nature and the denaturing of the social, which he rejects. Byrne (1998:46) relies on the critique by Mouzelis (1995) which cites the failure of poststructuralism to account for the way that discourse is embedded in hierarchical and inequitable structures of power. Byrne disparages the way in which it leads to abandonment of the role of the intellectual by encouraging inaction and disengagement. It is "bone idleness promoted to a metatheoretical programme" (1998:45). He contrasts it with his own view of complexity science in which "humility about the complexity of the world [is] coupled with a hopeful belief in the potential of human beings for doing something about it" (1998:45).

A second major approach to complexity in the social sciences can be seen in studies that draw upon an emerging vocabulary of complexity to conceptualize specific social phenomena. For example, Robert Artigiani (1987:250-256) applies Prigogine's model of dissipative structures to revolutions, tracing the development of the state from feudal to modern times. He examines how social structures reach points of instability and provide an arena in which significant changes occur in both their struc- 
ture and in the behaviour of persons. Changes in the way war was waged, the creation of standing armies and emergent classes have all led to the modern state. Revolutions occur when there is "feedback from environmental fluctuations sufficient to amplify minor shifts in open systems far from equilibrium" (1987:254). They are seen, then, as a moment in an evolutionary phase shift reflecting the history of the society, which is unpredictable and not determined by other forces. Peter Knapp (1999) examines the use of self-reinforcing processes in macrosociological models derived from historical theories. He traces three examples from systems theory: Myrdal's work on vicious cycles in American racism, Collin's model for revolution and transformation in the welfare state, and Chase-Dunn and Hall's model of socially structured inequality. ${ }^{4}$ Knapp argues that positive feedback processes are not only crucial in all three types, but they also illustrate similarities between complex nonlinear analysis and dialectical theories. Garcia (2000) approaches sustainable development as complex, unpredictable, and operating in a context of entropy. He argues that mechanistic epistemologies have been applied to both development and sustainability, so the paradigm of sustainable development can be little more than a prisoner of the basic myths of European patriarchy. Since "no material process can last indefinitely in a finite environment, and no material can be recycled in an indefinite way ... the notion of sustainable development is essentially contradictory" $(2000: 248)$. As a result, he is pessimistic about current formulations regarding development and sustainability.

Robert Urry $(2003$; 2005) favours complexity over conventional linear approaches for theorizing of globalization. He expands upon the work of Castells $(1996 ; 1997 ; 1998)$, using concepts such as dissipative structures, emergence, nonlinear relations, bifurcation points, strange attractors, and autopoiesis to describe globalization. He also draws on concepts from poststructuralism such as actor-network theory and fluids (Mol and Law 1994). Urry argues that conventional notions such as society, nationalism, structure, and agency have become passé due to mobility and fluidity of the social in contemporary life (2003:121-122). He appears fascinated with positive feedback loops, for example, in developing the concept of "glocalization" - a "globalization-deepenslocalization-deepens-globalization" process (2003:15). It is applied to "computime" and the spatial indifference of information, the location of the Olympics, the Zapatistas, and failure of the WTO (2003:85-89). ${ }^{5}$

4. Chase-Dunn and Hall do use both positive and negative feedback loops, but in this article, Knapp emphasizes the former.

5. With regard to the latter, his analysis is problematic. There is significant evidence suggesting that the failure of the WTO Ministerial in Seattle was due to organized resis- 
This rush to the global is further illustrated in his stress on fluidity and the rise of cosmopolitanism, which he argues will remake social relations around the world (2003:137-140). He argues that complexity "is the theory that cosmopolitanism produces and generalizes, that captures and reflects the systemic features of powerful material worlds" (2003:140). In a later publication, Urry (2005) focusses on what appears to be a transposition of the notion of false consciousness, where phenomena such as the internet, automobility, social movements, and smart mobs are described as "flows of emotional or charged energy [or] nonlinear switches in organization that can occur once a threshold is passed" (2005:245-249). This appears to have replaced glocalization as he reaffirms an earlier view that Marxism is the best example of complexity analysis, now seen as a basis for metaphors for analyzing "global dis/ order" (2005:254).

Erika Summers-Effler (2007) utilizes complexity notions by applying the metaphor of turbulence and the concepts of emergence and collapse to organizational life cycles. Turbulence is applied to methodological issues since the relative distance of the observer from the organization affects what is discovered - with observers and observed never being able to escape the turbulent flow $(2007: 444)$. Further, the proximity of an observer to the centre of action accounts for whether an observer views stability or movement through cycles in the organization. Organizational emergence and collapse are associated with phase changes whereby instability is absorbed until a critical point is reached, when organizing processes of a different type emerge (2007:438).

Walby (2007:458-459) undertakes a "hybridization of complexity theory" in order to theorize inequality associated with intersectionality. Class, gender, and race - the usual elements of intersectionality - are seen, not as institutions, but as relational structures. These relational structures are seen as systems that are not nested, do not saturate the territory they inhabit, but are emergent and co-evolve. They are seen as path dependent and characterized as far from equilibrium, operating primarily through positive feedback loops. She proposes that the conventional concept of society be replaced by "societalization" to facilitate analysis of more adaptable and diverse systems of social organization.

From this review, several observations can be made. First, there is fairly strong support from several disciplines for the need to explore complexity. Within sociology, efforts to appropriate complexity as an invigorating attractor have been proposed from within the order, conflict, and poststructuralist domains. Second, despite differences in orien-

tance by developing countries and antagonistic practices of the two major parties, the US and the EU. See, for example, Bayne (2002), Raghavan (2000). 
tation, there is agreement on the need to move beyond the conventional paradigm of linear sociology when addressing complex situations, arrangements, or problems. This includes the need to see the social as open, dynamic, self-organized around attractors, contingent, and nonlinear. Third, flowing from this is an acknowledgement that complexity undermines confidence in linear or rule-based strategies and pursuit of universal laws of social activity. For example, Luhmann proposed a universal theory of society which carried an incumbent paradoxical standpoint from which to work; Cilliers, skeptical of foundationalism, retreats to domains of linguistic stability and Byrne insists that knowledge is now local and contextual. Fourth, there has been an enthusiastic "discovery" of positive feedback loops (e.g., Knapp and Urry) while negative feedback loops have been neglected. Fifth, the principal theorists (and others) have failed to develop the notion of morphogenesis despite being concerned with the dynamics of structural change. Luhmann makes only passing reference to morphogenesis, apparently reducing it to positive feedback loops (1995:351-356). All the while, he addresses increasing complexity of subsystems through the notion of functional differentiation (institutions) to characterize its organization. Cilliers sees structure as arising only through microlevel units organized around nonlinear relations that are distributed, weighted, and stored as traces of memory (1998:94-95). For Byrne, complexity is inherently systemic and can be portrayed by the analogy of a dissipative structure while the social is portrayed as a trajectory resulting from structural organization around attractors in nonlinear relations (2003:22-31). Despite increasing support for exploring complexity and the emergence of a vocabulary of complexity, the notion of morphogenesis has not been developed and there is a need for an analytical technique that can utilize positive and negative feedback loops. Together they present the need for development of a more unified strategy that links ontological, epistemological, and methodological concerns.

\section{A Realist Ontology}

In the remainder of this paper I connect a nonlinear technique for analysis with epistemological and ontological formulations that can serve an analytical strategy for exploring complexity. This reflects the review above which suggested a need to explore ontological and epistemological positions that are appropriate for complexity and to devise a more specific method of analysis. The first is dealt with by linking the critical realist approach to morphogenesis and the morphogenetic epistemology 
set out by Magorah Maruyama. Maruyama apparently was the first to devise a specific technique that can utilize both positive and negative feedback loops for analysis of complex situations. There have been other attempts to develop techniques that address nonlinear phenomena. David Byrne (1998; 2002; 2005), for example, has addressed this problem in a number of ways and as noted above, he situates his work within critical realist ontology. There is, however, still need to bring Maruyama's epistemology and his analytical technique to light and to outline these congenial orientations to morphogenesis. The discussion begins with the work of the critical realists on ontology and morphogenesis.

Critical realism is concerned first of all, with real structures that endure and operate independently of our knowledge and experience. Following Bhaskar (1975; 1998a; 1998b), critical realists begin from the dual understanding that scientific knowledge is socially produced, yet it is primarily knowledge of things that are not produced by humans. They locate their work close to the philosophy of science, since they hold that through it one can use knowledge of science to infer certain features of the world that cannot be established by philosophical analysis alone. Central to this project is re-establishing investigation into ontological questions (the nature of being) through a revised understanding of science and the world of activities that happen independently of our knowledge of them. They propose that the world be seen as stratified, consisting of three domains: the real, the actual, and the empirical (Bhaskar 1998a:41-43). The first of these, structures and mechanisms - the intransitive, the real - are the generative things of the world (e.g., gravity). These mechanisms endure whether or not they lead to actual patterns of events. Those patterns of events may not result because of countervailing causes or other mechanisms that intervene. In any case, it is the actual pattern of events that laws are about, not the empirical experience of events. Laws, then, are not about universal empirical regularities, but are expressive of structures, powers, mechanisms, and tendencies.

Bhaskar asserts that the aim of science is to discover the independently existing and transfactually active machinery of nature. Since it is not plausible to imagine science without intransitives, Bhaskar (1998a:18) argues that it is reasonable to ask, "what must the world be like for science to be possible." In contrast to the empiricist ontology that revolves around experience, Bhaskar (1998a:23-26) seeks an ontology built around the intransitive and structured character of the objects of scientific knowledge. He argues that there is intelligibility in both sense perception and experimental research in science that provides this justification, but that they do so in a manner that is transfactual and stratified. He extends this argument to the social as well, positing: that societies are 
irreducible to people; they are a necessary condition for any intentional act; their pre-existence establishes their autonomy as possible objects of investigation; and their causal power establishes their reality. The causal power of social forms is mediated, however, through human agency and the dynamics in this activity are summarized in a transformational model of social action (TRSA) (Archer 1998c:358; Bhaskar 1998a:23-26). The critical realist strategy derived from Bhaskar's TRSA examines the ways in which structure both constrains and enables activity as well as how that activity reproduces and transforms structures. That is, if society is a pre-existing condition for agency, it also persists only as a result of human activity. This inability to persist without being reproduced or transformed was referred to by Bhaskar as the activity-dependence of society. Bhaskar held that engagement in a social activity is a conscious human action that may be described in one of two ways: either in terms of the agents' reason or of its social function - although necessity in social life operates in the last instance via the intentional activity of agents. It was necessary, then, to distinguish between the two, for example, as Bhaskar noted, one does not suppose that the reason why garbage is collected is necessarily the garbage collector's reason for collecting it (though it depends upon the latter) (Bhaskar 1998b:216). Nor is it believed that people marry in order to reproduce a family system or work to perpetuate capitalism although these are both conditions for and consequences of these activities (Bhaskar 1998b:209-10).

Critical realism has generated lively discussion, partly because it challenges empiricism, poststructuralism, and structurationist theoretical positions. Designed as a philosophical infrastructure with affinity to Marxism, even that linkage has been challenged (Fine 2006). Despite that, there have been a number of spirited social scientific responses, often not so much in disagreement with Bhaskar's project as with the manner in which he has gone about it. Four of these have relevance here and will be briefly discussed: Bhaskar's conceptualization of the real, the actual, and the empirical; his characterization of science; his view of the relation between structure and agency; and the underutilization of sources from the social sciences which could justify his project.

Bhaskar's distinction between the intransitive and transitive dimensions involves distinguishing between the real, the actual, and the empirical, a matter that Sayer approaches from within a Marxist framework. He agrees with Bhaskar that knowledge is grounded in the a posteriori, but he sees a need for more explicit consideration of the way in which concepts change with the reality they depict (Sayer 1997; 1998). This can be seen especially with regard to the relation between the abstract and the concrete. In Sayer's view, the abstract refers to statements re- 
garding tendencies in natural - rather than logical - necessity which concern crucial mechanisms such as the conduction of electricity, or, in the social sphere, the relation between capital and labour. More specifically, in terms of Marxist theory, the abstract includes: 1) concepts within historical materialism regarding people and nature; 2) transhistorical claims (such as the social relations of production); 3) historical abstractions of necessary relations (capital and wage labour); and 4) mechanisms operating by virtue of those necessary relations (the law of value) (1998:129). The concrete is not simply empirical, but a contingent conjunction of a number of necessary relationships that are stratified and only understood through research (1998:127-128). In this way Sayer brings more specificity to the work of Bhaskar.

Pearce (2007) also has concerns about Bhaskar's failure to clearly develop his distinctions between the real, the actual and the empirical. He points out that they are used inconsistently and that Bhaskar is vague about the way the terms are used (2007:50-53). He suggests that if they were approached as relational, rather than in a categorical manner, it would allow exploring the interrelationship involved in changes in scientific knowledge and the process of conceptualization.

Similarly, Benton (1998) points out that Bhaskar's argument for establishing the intransitive through the conditions of the possibility of science ("what must the world be like for science to be possible?") involves vague references to science. He points out that Bhaskar sometimes refers to the "existence of science," other times to the "intelligibility of science" and even the "rationality of science" - terms that have different significance. He adds that by relying on experimental science as the exemplar for his argument, Bhaskar is committed to a form of epistemological dualism commonly found in the contrast between natural and social sciences. Because alternative empirical control techniques are found in a variety of sciences, the focus on experimental science does not seem necessary. This leads Benton to chide Bhaskar, proposing that the natural sciences are more like the social sciences that Bhaskar supposes (Benton 1998:311).

A third area of criticism concerns Bhaskar's interpretation of the relation of structure to agency. Benton thinks Bhaskar leaps to the conclusion that subjects cannot treat social structures as independent objects because they participate in them. On the contrary, Benton argues that it is possible to sustain the existential independence of social structures while conceding causal interaction of subject and object (Benton 1998:308). Pearce (2007:43) shares this view, noting that Bhaskar relies on a model of human subjectivity which is too intentional, and that leads to an underestimation of the possibility of establishing the reality of 
social structure. Both Benton and Pearce also address Bhaskar's claim that social structures are dependent upon activity of persons. Benton points out that if that were so, then Bhaskar would have to concede that knowledge of the social could not lead to knowledge of the intransitive, but only to philosophical knowledge (Benton 1998:300). This critique is mitigated since Benton thinks that many of Bhaskar's difficulties are methodological rather than epistemological. He suggests that a correction of Bhaskar's arguments would likely lead to a confirmation of the general model (Benton 1998:311). Regarding structure and agency, Pearce (2007:60) is more emphatic. He states, "the sociological levels are distinct and include causal levels that make no reference to "individual human agency'."

A fourth area of criticism is developed fully by Pearce (2007:52-60) who shows how Bhaskar's view could be enhanced by adopting Marxist and Durkheimian conceptualizations of the social. With regard to the former, Pearce argues that the critical realist concern about avoiding the epistemic fallacy (the reduction of ontological questions to matters of epistemology) could be realized by including the Marxist distinction between real objects and thought objects - akin to the more relational conceptualization noted above. Pearce also shows how Durkheim's conception of the social is richer than Bhaskar acknowledges, providing for structures that are persistent, adaptable, and providing channels within which individuals can pursue activities that have tranformative potential.

These are constructive critiques of the critical realist project - a task more fully undertaken by Margaret Archer (1998a; 1998b; 1998c), whose formulation follows her own work on morphogenesis. I will focus here on her discussion of the relevance of Bhaskar's model for practical social theory. Archer proposes that an ontology of the social be sought by examining social relations exemplified by structure and agency. She begins with two propositions: 1) that structure necessarily predates the actions which transform it; and 2) that structural elaboration necessarily postdates those actions (1998c:202). These enduring relations are dynamically related in that all activity is prestructured and yet structures are dependent on activity if they are to persist. Social reality is likened to a series of riddles: what is it that depends upon intention, but never conforms to it; relies on conceptualizations which people never follow; is activity dependent but never corresponds to their activities; has no organizational form without persons, yet is formative; and is constituted in a manner that never satisfies, yet motivates people to further its reconstitution (Archer 1998a:190)? Archer refers to this as the riddle of structure and agency, which has four major types of resolution: 1) reduction to a world of individual people; 2) reduction to systems or structures 
with deterministic powers; 3 ) mutual constitution by duality of structure manifest only in the present through instantiation by agents (Archer refers to this as elisionism and it includes structurationist and poststructuralist approaches); and 4) realism, which is further discussed below.

Archer qualifies Bhaskar's views in order to avoid epistemological dualism or the dualistic structure employed by structurationists and poststructuralists. This is done through an analytical dualism revolving around the notions of structure and agency. She responds to Benton's concern about Bhaskar's overreliance on the dependence of structure on agency. She argues that structure and agency include mediating systems consisting of positions and practices that come into play (Archer 1998a:200). Actors have contact with structure through positions, viewed broadly as positions in which they find themselves, whether in problematic situations or contexts of interaction (Archer 1998c:372). As Archer says: "positions must predate the practices they engender: although activity is necessarily ceaseless for society to be, it is discontinuous in nature because changes in society's structure then condition practices in distinctively different ways" (1998a:201). As a result, social interaction is patterned by the variety of conditions that affect the position and the variety of resources and vested interests associated with it. In this way, it is possible to talk about emergent properties that are a result both of the past activities of agents and current agents whose actions are conditioned by these structural and cultural contexts. Archer further argues that emergence can be understood as combinations of social relations involved in transforming a structure. She uses the schema Structural conditioning $\rightarrow$ Social interaction $\rightarrow$ Structural elaboration to illustrate how morphogenesis can be derived from the structure/agency relation. This distinguishes it from structuration, which involves a conflation of the two (1998a:202). These nonlinear relations then have the potential to account for the reproduction and transformation of structures. Through this conceptualization, she argues that Bhaskar's ontological grounding can be translated into practical social theory in a manner that is congruent with the work of Sayer (1998:372).

The critical realist development of an ontological framework for social theory derives primarily from the work of Roy Bhaskar, but a cadre of critics has augmented it. Rising from the space created by the demise of empiricism and positivism and the unsettling rise of discursive studies, it sought to place the epistemological impasse in the broader context of ontology. The result has been, especially in the work of Archer (1998a; 1998b; 1998c), a strategy that addresses structural change and interactional processes as a dynamic confluence of activity. It enables congruent epistemological and methodological strategies to be set out. 


\section{A Morphogenetic Epistemology}

Magorah Maruyama (1980) proposed an epistemological strategy that is clearly congenial with the ontological position of the critical realists. He approached these matters more as an anthropologist and practitioner than as a philosopher, focusing primarily on the contrasting ways that causality has been conceptualized in different cultures and domains of science. Four major epistemological models for constructing knowledge in science were seen as predominant: 1) nonreciprocal causal models, in which the components involved relations between homogenous variables (that is, analysis revolved around variables within rather than between discrete levels of abstraction); 2) independent-event models based on the random distribution of events that are heterogeneous (analysis revolved around variables between discrete levels of abstraction); 3) homeostatic causal-loop models which analyze patterns or structures based on heterogenistic variables that are maintained through negative feedback causal loops; 4) multilateral mutual causal-loop models based on negative and positive feedback loops between heterogenistic variables.

The first of these, the nonreciprocal causal model, is what has traditionally been associated with scientific method. In this approach, causation is conceptualized as influence that flows from "cause" to "effect" in a nonreciprocal manner among variables that are homogenous in nature. The rationale is to discover probability distributions by which the latter can be inferred from the former with varying degrees of probability. Success involves identifying relations between variables due to nonreciprocal relations, as a result of direct or indirect influence. Since the causal direction cannot be known from the statistical inferences alone, they must be grounded in some logical framework. Maruyama was not as interested in critiquing this model as he was in using it as a contrast to the others, especially the most recent, the multilateral mutual causalloop model. The second model, the independent-event model, was based on logic and mathematics associated with probability as developed in thermodynamics and information theory (Caley and Sawada 1994). It has been associated with the rise of quantum physics and bases epistemological procedures on locating associations deriving from a template of independent and random events (Pribram 1986). The third and fourth models differ from the first two because they are based on a loop epistemology. Loop epistemology is not what is commonly thought of as simple circular causation, but may involve multilateral, mutual, simultaneous causality, with the result that the same initial conditions may produce entirely different outcomes. Homeostatic causal-loop models are closely associated with functional models in anthropology, sociol- 
ogy, psychology, and economics, stressing the notions of equilibrium and self-regulation. Maruyama (1960:84) referred to this arrangement of relations as "morphostasis," because the effects of the loops were toward equilibration in a system. Maruyama saw the limitations of this approach for analyzing change and proposed an alternative. For this model he used the term, "morphogenesis," to indicate that the focus was structural change (Maruyama 1980:590). This was proposed as early as 1962 in an article demonstrating that differentiation-amplifying causal loops which generate heterogeneity were an indispensable process within a system (Maruyama 1962). In this model, explanations employ both positive and negative feedback loops and autocatalysis (the speeding up of a reaction by a catalyst that is a product of the reaction). The key elements are probabilistic or deterministic loops of mutual causality that can increase the pattern of heterogeneity towards higher levels of organized complexity. Maruyama (1960:84) referred to them as deviation-amplifying mutual relations, showing that in these situations "[A] small initial deviation, which is within the range of high probability, may develop into a deviation of very low probability," again contradicting the view in normal science that "the same cause produces the same effect." Morphogenesis, then, refers to a "generation of structuredness," which can occur through amplification of relations, rather than through the equilibrating structuring that is found in relations that tend to have a negative feedback result (Maruyama 1980:85). It is the morphogenetic causal-loop model that holds promise for understanding complex systems, largely because the combination of deviation-amplifying mutual relations and already-employed homeostatic loops provide a new way to conceptualize structural change that is sensitive to a variable series of component loops.

\section{A Technique for Nonlinear Analysis (Following the Work of Margorah Maruyama)}

Drawing on the morphogenetic causal-loop model makes it possible to conceptualize complex systems as loops so that their structure and the activities within them constitute a illustrate tendencies toward stability (morphostasis) or change (morphogenesis). That is, loops can take either an equilibrating or deviance-amplifying direction. This method of analysis (Maruyama 1962), proceeds by: 1) identifying key activities or components; 2) establishing the way they are linked in mutually causative loops; 3 ) identifying whether the loop is equilibrating (negative feedback) or escalating (positive feedback); and 4) assessing the overall pattern of the system. A nomenclature for listing the components 
in a loop and a method for calculating whether a loop is equilibrating or escalating was also developed by Maruyama. The basic approach can be illustrated fairly directly, so below I present several examples, beginning with one from Maruyama's 1962 (173-175) study, dealing with population and health in cities at varying levels of modernization, as shown in Figure I.

Figure I: Maruyama's schema for population, modernization and sanitation

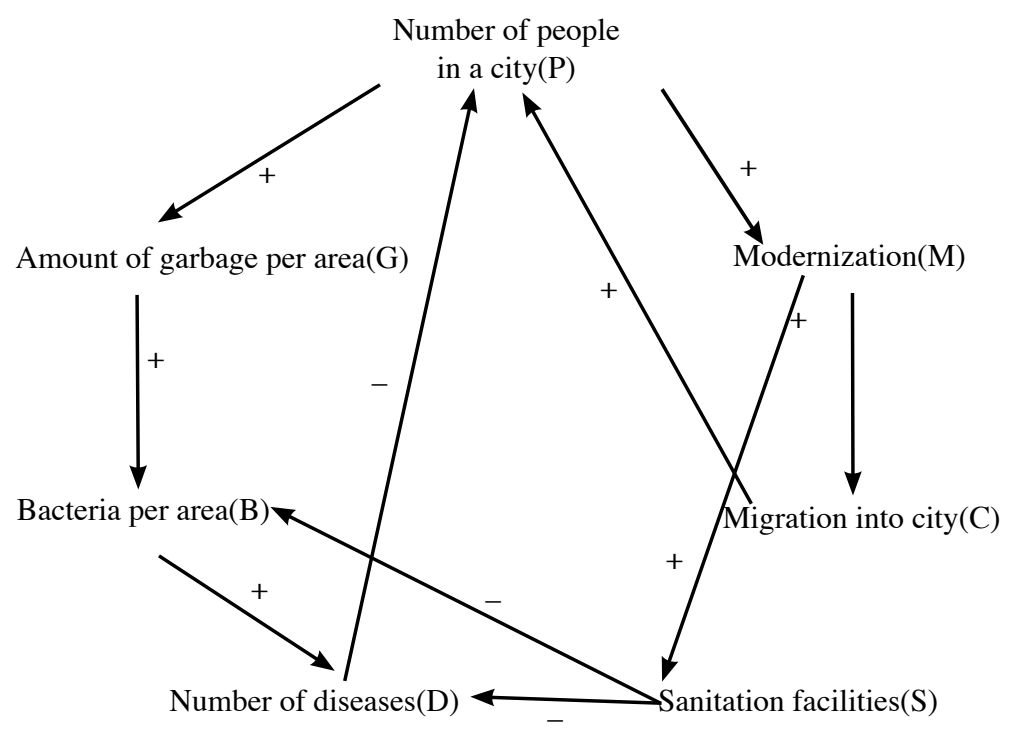

This diagram serves to introduce a nonlinear method for analyzing complex systems, although it is a rudimentary example. In the diagram is a series of arrows that connects the elements. Any number of items could be selected, but these emerged as primary. Obviously, a greater number of elements will increase the possible number of loops. Maruyama identified six variables that can affect the potential population of a city: extent of modernization, migration, amount of garbage, bacteria in an area, number of diseases and sanitation facilities. He then identified four loops that can account in varying ways for the increase or decline of the populations in the cities. They are:
1) $\mathrm{P}+\mathrm{M}+\mathrm{C}+\mathrm{P}$
Escalating
2) $\mathrm{P}+\mathrm{G}+\mathrm{B}+\mathrm{D}-\mathrm{P}$
Equilibrating
3) $\mathrm{P}+\mathrm{M}+\mathrm{S}-\mathrm{D}-\mathrm{P}$
Escalating
4) $\mathrm{P}+\mathrm{M}+\mathrm{S}-\mathrm{B}+\mathrm{D}-\mathrm{P}$
Escalating 
It is instructive to contrast the various loops and assess their total impact. That is, in loops 1, 3, and 4 an amplifying impact is shown, as when modernization, migration and population reinforce each other. On the other hand, loop 2 is equilibrating, for as population increases, so does garbage and the extent of bacteria, which in turn increases disease, leading to a decline in population. In order to distinguish these kinds of loops, I use the terms "escalating loops" and "equilibrating loops." In the former, the relations between the elements are such that we have an escalation of effect, while in the latter, the effect is moderated or equilibrated. The calculation of whether or not a loop is escalating or equilibrating requires a bit of explanation. The + should be interpreted to mean that if the first term (e.g., population) increases, then the second term (modernization) is likely to increase. It also means that if the first term decreases, then the second is also likely to decrease. A designation of - means that if the first term (sanitation facilities) increases, then the second term (disease) is likely to decrease. Or, conversely, that if the first term decreases, then the second term is likely to increase. Maruyama (1962:175-178) suggested a simple way of telling whether loops are escalating or equilibrating. An even number of -'s (or negative loops) represent an outcome of positive feedback (zero is included as an even number). Such is also the case when all relations are positive. Loops in which there are an odd number of -'s is considered an equilibrating, or negative feedback loop. In brief, this formulation makes it possible to identify a set of relations that can account for an outcome by stating the relative impact of the same elements and the way in which they can contribute to differential outcomes.

For a second example, I turn to a different scale of social activity and a classical case that is apt for this type of analysis: the moral panic. This phenomenon, popularized when it was first introduced in connection with public responses to "folk devils," explicitly draws on the notion of deviance amplification, noted here as an escalating loop (Cohen 1972).

Figure II: Loops in a Moral Panic

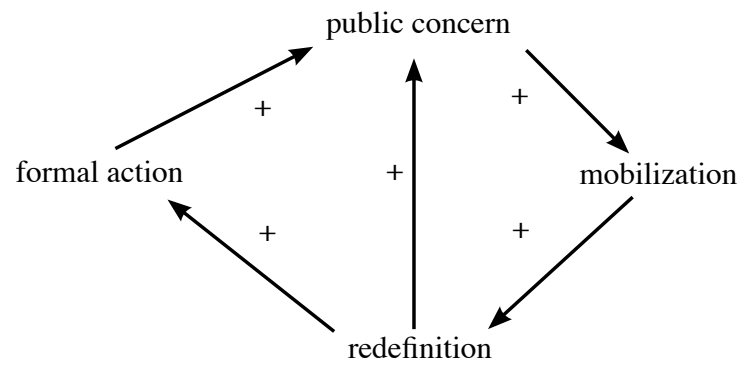


In this case, a public fear or concern leads to further mobilization, often as a result of heavy publicity by the media. As these panics grow and a wider portion of the population becomes involved, the concern is redefined. One result is that the increased organization contributes to further escalation as can be seen in Loop 1. If the mobilization leads to an organized political response, it may be that this can lead to further fear and concern. In fact, this mobilization may be co-opted and used in a political manner. This would also reinforce the escalation of the panic as is seen in Loop 2. This would be illustrated through the following loops:
1) $\mathrm{C}+\mathrm{M}+\mathrm{R}+\mathrm{C}$
= Escalating
2) $\mathrm{C}+\mathrm{M}+\mathrm{R}+\mathrm{A}+\mathrm{C}$
= Escalating

It should be noted, however, that a question soon rises as to when, if ever, and how a moral panic ceases (Ditton 1979). Two apparent responses are readily available: first, that the redefinition can be seen by the public as sufficient to diminish the concern, or second, that the formal action can have a similar result. In such a case, the loops would be properly described as:
3) $\mathrm{C}+\mathrm{M}+\mathrm{R}-\mathrm{C}$
$=$ Equilibrating
4) $\mathrm{C}+\mathrm{M}+\mathrm{R}+\mathrm{A}-\mathrm{C}$
$=$ Equilibrating

Extending this example to a more realistic level, we can explore hypothetically the way in which a particular group of "folk devils" and other parties respond or adapt to a situation that may involve deviance. While official responses may dampen the activities, another result could be enhanced publicity and a market in which the "folk devils" can defend themselves or even expand. Figure III presents an illustrative series of terms and links, without identifying all the loops that would be involved.

\section{Figure III: Schemata of a "Folk Devils" situation}

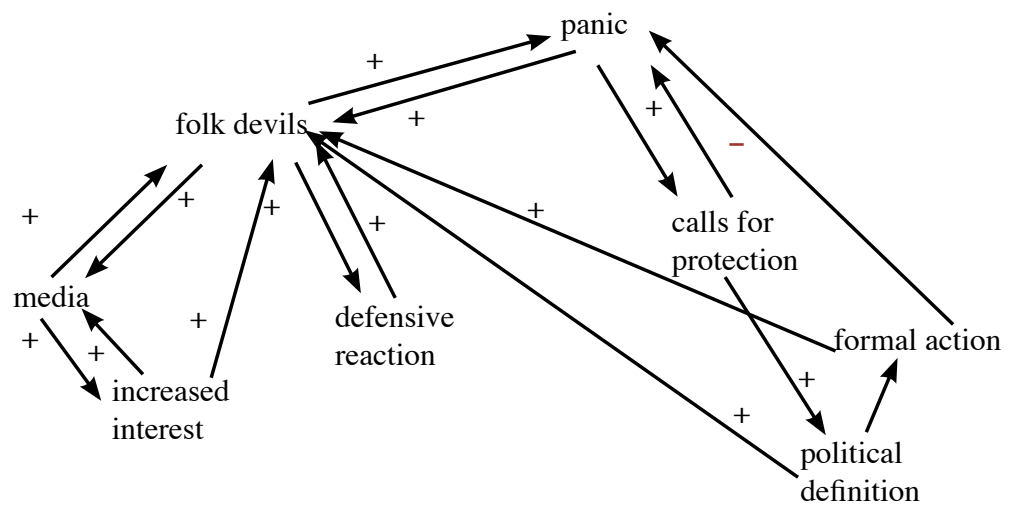


It is used to show the way in which this technique for analysis can facilitate combinations of complementary and contradictory social relations that are operative in a complex situation in a relatively orderly manner.

In the ecosystem approach to complexity noted above, when a number of loops in a complex system can be seen to revolve around a particular activity or component, that component is referred to as an attractor (Kay and Regier 2000; Mackenzie 2005). Importing the notion of the attractor into the techniques of multilateral mutual causal analysis allows expansion into more detailed examinations of structural change. This can be illustrated by beginning with an example from ecosystems research concerning the regeneration of a lake when it flips from a eutrophic state to an oligotrophic state. Due to the dynamics of deviation-amplifying mutual relations within each state of the lake, there can be unpredictable shifting back and forth. That is, it is self-organizing with self-sustaining capabilities which respond to change in contextual elements (e.g., phosphorous loading) beyond critical thresholds (Kay and Regier 2000). Given the nature of the loops and the variable pressure toward equilibration and escalation, the ecosystem at a certain point in time behaves as if it were attracted in a particular way. When these lakes are studied closely, it can be seen that within the shallow lakes there are a variety of loops and there is a propensity for the ecosystem to organize around a relatively central focus, the attractor (Kay and Regier 2000:131). Kay and Regier (2000:132) identify two attractors that coexist in shallow lakes, the benthic (happening on the bottom) and the pelagic (happening at the surface). With the former, the water at the top is clear so that sunlight penetrates deeply into the lake, while in the latter the water has become highly concentrated by nutrients and is turbid. They show that shallow lakes "flip" from one of these states to another in ways that may be dramatic and even unpredictable. The attractor represents a focus that could be characterized as an equilibrium point where the various loops are balanced. But it could be one of several such attractors. Kay and Regier state that in any given ecological situation there are several potential attractors, whose existence is constituted in relation to the loops that have been identified in the ecosystem. Establishing a definitive structure to describe such a lake is problematic since the shifting or "flipping" as when a lake flips from one attractor to another, or back again - is highly variable and can depend on unpredictable accidents.

Taking this line of thought further, and more directly to the social, extend it to the notion of the "universal" in Gramsci's work on hegemony (Gramsci 1971). Hegemony involves a process whereby a population comes to be dominated through its own consent (Gramsci 1971:181183). This is accomplished through the establishment of a "universal," 
that is, a discursive construction which invokes a commanding claim on political activities, such as "economic growth." The "universal" serves as a discursive centrepiece in a hegemonic arrangement, justifying an agenda in which both coercive and consent-generating processes are played out. The "folk devils" in Figure III can be seen in this light. That is, they may serve as the attractor for a program of formal action, perhaps involving a "law and order" crusade. At the same time, activities of the "folk devils" may also attract people to them. As a result, the structural arrangement and possible "flipping" between actual and ritualized enforcement that may emerge can be explored through these techniques. Approaching a "universal" with the notion of an attractor and multilateral mutual causal analysis makes it possible to explore the way in which power can be structured or resisted by identifying relations with implications for reproducing or transforming a structure. In sum, these techniques and the corresponding epistemology and ontological formulations provide a promising and fairly consistent strategy for analysis.

\section{Conclusion}

This paper began from the premise that if contemporary issues and problems can be characterized as complex, and conventional linear analytical strategies of normal science are limited in addressing them, then exploring alternative approaches to complexity is justified. The aim has been to clarify the nature of complexity and set out a strategy for nonlinear analysis. To that end, complexity is defined as a type of intricate relationality constituted in and around structures that are self-organizing, dissipative, dynamic, nonlinear, indeterminate, and usually associated with systems. Complexity was distinguished from chaos, which is seen as a precursor and manifestation of complexity.

From a review of four domains of inquiry, especially the social sciences, five key points emerged: 1) There is support for the importance of exploring complexity in a variety of scholarly areas. 2) It involves a call to move from linear strategies to ones that can investigate systems that are open, dynamic, self-organized around attractors, contingent, and nonlinear. 3) There was an acknowledgement of the limitation imposed by complexity on social science based on linear, rule-based strategies and the pursuit of universal laws. 4) It became apparent that there is a need to develop an analytical technique that can utilize both positive and negative feedback loops. 5) It was also clear that morphogenesis has not been generally integrated into strategies for analysis of structural change. 
The remainder of the paper focussed on addressing the two deficiencies that were identified by connecting a nonlinear technique for analysis with epistemological and ontological formulations as the basis of an analytical strategy for exploring complexity. It appears that Archer's formulation of morphogenesis is congenial to the multicausal mutual causal epistemology and the technique for analysis of nonlinear relations developed by Maruyama. Combining the notions of the attractor and Gramsci's "universal" provided an illustration of the potential value of morphogenetic causal loop models for analysis of the structuring and potential connections through which structures are either reproduced or transformed.

\section{REFERENCES}

Allen, T.F.H. and T.B. Starr. 1982. Hierarchy: Perspectives for Ecological Complexity. Chicago: University of Chicago Press.

Archer, M. 1998a. Critical naturalism and social science: Introduction-realism in the social science. Pp. 189-205 in Critical Realism: Essential Readings. London: Routledge. 1998b. Introduction: Realism in the social sciences. In Critical Realism: Essential Readings 189-205. London: Routledge. 1998c. Realism and morphogenesis. Pp. 356-81 in Critical Realism: Essential Readings 356-81. London: Routledge

Artigiani, R. 1987. Revolution and evolution: Applying Prigogine's dissipative structures model. Journal of Social and Biological Structures 10:249-64.

Baecker, D. 2001. Why systems? Theory, Culture \& Society 18:59-74.

Back, Kurt W. 1997. Chaos and complexity. In R.A. Eve, S. Horsfall, and M.E. Lee, eds., Chaos, Complexity and Sociology. Thousand Oaks, CA: Sage Publications

Bainbridge, W.S. 1997. The omicron point: Sociological application of the anthropic theory. Pp. 91-101 in Chaos, Complexity and Sociology. Thousand Oaks, CA: Sage.

Bak, P. and K. Chen. 1991. Self-organized criticality. Scientific American: 46-53.

Baudrillard, J. 1988. The Ecstasy of Communication. New York: Semiotext(e).

Baumgartner, T. 1986. Actors, models and limits to societal self-steering. In Sociocybernetic Paradoxes: Observation, Control and Evolution of Selfsteering Systems. London: Sage.

Bayne, N. 2002. Why did Seattle fail? Globalization and the politics of trade. Government and Opposition 12:131-53. 
Benton, T. 1998. Realism and social science: Some comments on Roy Bhaskar's "The possibility of naturalism." Pp. 297-312 in Critical Realism: Essential Readings. London: Routledge.

Bhaskar, R. 1975. A Realist Theory of Science. London: Version. 1998a. Philosophy and scientific realism. Pp. 16-47 in Critical Realism: Essential Readings, London: Routledge. 1998b. Societies. Pp. 206-57 in Critical Realism: Essential Readings. London: Routledge.

Bjerg, O. 2006. Accelerating Luhmann: Toward a systems theory of ambivalence. Theory, Culture \& Society 23:49-68.

Byrne, D. 1998. Complexity Theory and the Social Sciences. London: Routledge. 2002. Interpreting Quantitative Data. London: Sage Publications. 2005. Complexity, configurations and cases. Theory, Culture \& Society 22:95-111.

Caley, M.T. and D. Sawada, eds. 1994. Mindscapes: The Epistemology of Magoroh Maruyama. Langhorne, PA: Gordon and Breach.

Castells, M. 1996. The Information Age. Vol. 1. The Rise of the Network Society. Oxford: Blackwell.

1997. The Information Age, Vol. 2. The Power of Identity. Oxford: Blackwell.

1998. The Information Age, Vol. 3. End of Millennium. Oxford: Blackwell.

Casti, J.L. 1994. Complexification: Explaining a Paradoxical World through a Science of Surprise. New York HarperCollins Publishers

Cilliers, P. 1998. Complexity and Postmodernism: Understanding Complex Systems. London: Routledge. 2005. Complexity, deconstruction and relativism. Theory, Culture \& Society 22:255-67.

Cohen, S. 1972. Folk Devils and Moral Panics: Creation of Mods and Rockers. London: MacGibbon and Kee.

Cornell, D. 1992. The Philosophy of the Limit. London: Routledge.

Ditton, J. 1979. Controlology. London: The Macmillan Press, Ltd.

Elliott, E. and L.D. Kiel. 1997. Nonlinear dynamics, complexity, and public policy: Use, misuse and applicability. Pp. 64-78 in Chaos, Complexity and Sociology. Thousand Oaks, CA: Sage.

Ellis, G.F.R. 2004. True complexity and its associated ontology. Pp. 607-36 in Science and Ultimate Reality: Quantum Theory, Cosmology and Complexity. Cambridge: Cambridge University Press.

Eve, R.A. 1997. Afterword: So where are we now? A final word. Pp. 269-80 in Chaos, Complexity and Sociology. Thousand Oaks, CA: Sage.

Eve, R.A., S. Horsfall, and M.E. Lee. 1997. Preface. Pp. xxviii-xxii in Chaos, Complexity and Sociology. Thousand Oaks, CA: Sage. 
Fine, B. 2006. Debating critical realism in economics. Capital \& Class 89:12129.

Funtowicz, S. 1998. Post-normal science - environmental policy under conditions of complexity. http://www.nusap.net/sections.php?op= viewarticle\&artid=13 (accessed November 24, 2005).

Garcia, E. 2000. Self-organizing complexity, conscious purpose and 'sustainable development.' In Environment and Global Modernity. Thousand Oaks, CA: Sage.

Goertzel, B. 1997. Chaos and pattern in complex systems. Pp. 153-59 in Chaos, Complexity and Sociology. Thousand Oaks, CA: Sage.

Gramsci, A. 1971. Selections from Prison Notebooks. London: Lawrence and Wishart.

Harvey, D.L. and M. Reed. 1996. Social science as the study of complex systems. Pp. 295-323 in Chaos Theory in the Social Sciences: Foundations and Applications. Ann Arbor: University of Michigan Press.

Hayles, N.K., ed. 1991a. Chaos and Order: Complex Dynamics in Literature and Science. Chicago: The University of Chicago Press.

1991b. Introduction: Complex dynamics in literature and science. Pp. 1-33 in Chaos and Order: Complex Dynamics in Literature and Science. Chicago: The University of Chicago Press

Holling, C.S. 1986. The resilience of terrestrial ecosystems: Local surprise and global change. Pp. 292-320 in Sustainable Development of the Biosphere. Cambridge: Cambridge University Press.

1994. Simplifying the complex: The paradigms of ecological function and structure. Futures 26:598-609.

Hübler, A. 2007. Understanding complex systems. In Complexity. http://www3. interscience.wiley.com/journal/38804/home.

Kauffman, S. 1993. The Origins of Order: Self-organization and Selection in Evolution. New York: Oxford University Press.

Kay, J.J. and H.A. Regier. 2000. Uncertainty, complexity, and ecological integrity: Insights from an ecosystem approach. Pp. 121-56 in Implementing Ecological Integrity: Restoring Regional and Environmental Human Health. Dordrecht: Kluwer Academic Publishers.

Kay, J.J. and E. Schneider. 1994. Embracing complexity: The challenge of the ecosystem approach. Alternatives 20:32-39.

Knapp, P. 1999. Evolution, complex systems and the dialectic. Journal of World Systems Research 5:74-103.

Lee, D. 2000. The society of society: The grand finale of Niklaus Luhmann. Sociological Theory 18:320-30.

Lincoln, Y.S. and G.S. Cannella. 2004. Dangerous discourses: Methodological conservatism and governmental regimes of truth. Qualitative Inquiry 10:5-14. 
Lloyd, S. 1990. The calculus of intricacy: Can the complexity of a forest be compared with that of Finnegans Wake? The Sciences 30:38-44.

Luhmann, N. 1989. Ecological Communication. Cambridge: Polity Press. 1995. Social Systems. Stanford, CA: Stanford University Press.

Mackenzie, A. 2005. The problem of the attractor. Theory, Culture \& Society 22:45-65.

Mannheim, K. 1961. Ideology and Utopia. New York: Routledge.

Maruyama, M. 1960. Morphogenesis and morphostasis. Methods XII:251-96.

1962. The second cybernetics: Deviation-amplifying mutual causal processes. American Scientist 51.

1978. The epistemological revolution: Prigogine and reciprocal causal logic. Futures: 240-42.

1980. Mindscapes and science theories. Current Anthropology 21:589608.

Maturana, H.R. and F.G. Varela. 1980. Autopoiesis and Cognition: The Realization of the Living Dordrecht: D. Reidel Publishing Co.

Medd, W. 2001. What is complexity science? Toward an 'ecology of ignorance.' Emergence 3:43-60.

Mingers, J. 2002. Can social systems be autopoietic? Assessing Luhmann's social theory. The Sociological Review: 278-99.

Mol, A.P.J. and J. Law. 1994. Regions, networks and fluids: Anaemia and social topology. Social Studies of Science 24:641-71.

Mouzelis, N. 1995. Sociological Theory: What went Wrong? London: Routledge.

Østerberg, D. 2000. Luhmann's general sociology. Acta Sociologica 43:15-25.

Pearce, F. 2007. Bhaskar's critical realism: An appreciative introduction and a friendly critique. Pp. 30-63 in Critical Realism and the Social Sciences: Heterodox Elaborations. Toronto: University of Toronto Press.

Porush, D. 1991. Fictions as dissipative structures: Prigonine's theory and postmodernism's roadshow. Pp. 54-84 in Chaos and Order: Complex Dynamics in Literature and Science. Chicago: The University of Chicago Press.

Pribram, K.H. 1986. The cognitive revolution and mind/brain issues. American Psychologist 41:507-20.

1996. Interfacing complexity at a boundary between the natural and social sciences. Pp. 40-60 in E.L. Khalil and K.E. Boulding, eds., Evolution, Order and Complexity. London: Routledge.

Prigogine, I. 1980. From Being to Becoming: Time and Complexity in the Physical Sciences. New York: W.H. Freeman and Co.

Prigogine, I. and I. Stengers. 1984. Order out of Chaos: Man's new Dialogue with Nature. Toronto: Bantam Books. 
Putnam, H. 1981. Reason, Truth and History. Cambridge: Cambridge University Press.

Raghavan, C. 2000. After Seattle, world trade system faces an uncertain future. Review of International Political Economy 7:495-504.

Ragin, C.C. 2006. How to lure analytic social science out of the doldrums: Some lessons from comparative research. International Sociology 21:633-46.

Reed, M. and D.L. Harvey. 1992. The new science and the old: Complexity and realism in the social sciences Journal for the Theory of Social Behaviour 22:353-80.

Saperstein, Alvin M. 1997. The origins of order and disorder in physical and social deterministic systems. Pp. 102-122 in R.A. Eve, ed., Chaos, Complexity and Sociology. Thousand Oaks: SagePublications

Sayer, A. 1997. Critical realism and the limits to critical social science. Journal for the Theory of Social Behaviour 27:473-88. 1998. Abstraction: A realist interpretation. Pp. 120-43 in Critical Realism: Essential Readings. London: Routledge. (Orig. pub. 1981)

Schneider, Eric. D. and James J. Kay. 1994. Complexity and thermodynamics: Towards a new ecology. Futures 26:626-647.

Shannon, C.E. and W. Weaver. 1963. The Mathematical Theory of Communication. Urbana: University of Illinois Press.

Smith, J. and C. Jenks. 2005. Complexity, ecology and the materiality of information. Theory, Culture \& Society 22:141-63.

Stewart, P. 2001. Complexity theories, social theory and the question of social complexity. Philosophy of Social Sciences 31:323-60.

Stofberg, J.A. 1988. Objectivity and the sociology of science. South African Journal of Philosophy 7:213-25.

Summers-Effler, E. 2007. Vortexes of involvement: Social systems as turbulent flow. Philosophy of the Social Sciences 37:433-48.

Thrift, N. 1999. The place of complexity. Theory, Culture \& Society 16:31-69.

Urry, J. 2003. Global Complexity. London: Polity 2005. The complexities of the global. Theory, Culture \& Society 22:23554.

Viskovatoff, A. 1997. Foundations of Niklas Luhmann's theory of social system.s Philosophy of the Social Sciences 29:481-516.

Walby, S. 2007. Complexity theory, systems theory, and multiple intersecting social inequalities. Philosophy of the Social Sciences 37:449-70.

Watson, J.D. 1968. The Double Helix: A Personal Account of the Structure of $D N A$. New York: Atheneum.

Wynne, B. 2005. Reflexing complexity: Post-genomic knowledge and reductionist returns in public science. Theory, Culture \& Society 22:67-94. 
Ken Hatt is Adjunct Professor of Sociology at the University of Victoria. He has previously studied resistance and reform in and around Canadian state hegemony through three waves of capitalism: the Metis following the fur trade; liberal and neoliberal reconstruction in Canadian criminal justice; and small agriculture in an era of global trade liberalization. He now addresses resistance, reform and hegemony around sociology and explores alternatives arising from key disruptors to normal sociology. 
